\title{
Ecological Risk Assessment of Construct Artificial Islands by Fault Tree Analysis Method in the Persian Gulf
}

\author{
Amin Ahmadi Givi ${ }^{1}$, Sepideh Karimi ${ }^{1}$, Mahdis Sadat ${ }^{1}$, Mahmood Zoghi ${ }^{1}$, Saeed Karimi ${ }^{2,}$, \\ Negar foroughi ${ }^{1}$, Bahram malekmohamadi ${ }^{2}$ \\ ${ }^{1}$ Department of Environmental Education, Management \& Planning, Faculty of Environment, University of Tehran, Iran \\ ${ }^{2}$ Department of Environmental Planning and Management, Faculty of Environment, University of Tehran, Iran
}

\author{
Email address: \\ karimis@ut.ac.ir (S. Karimi)
}

\section{To cite this article:}

Amin Ahmadi Givi, Sepideh Karimi, Mahdis Sadat, Mahmood Zoghi, Saeed Karimi, Negar foroughi, Bahram malekmohamadi. Ecological Risk Assessment of Construct Artificial Islands by Fault Tree Analysis Method in the Persian Gulf. International Journal of Environmental Monitoring and Analysis. Vol. 3, No. 3, 2015, pp. 139-146. doi: 10.11648/j.ijema.20150303.15

\begin{abstract}
Development is inevitable in various sectors.One example of these developments is the construction of artificial islands which is man-made and is made for variety of purposes including tourism, economy, and airports, industrial, political and military establishment. Construction of artificial islands is a serious treatment for marine ecosystems. In this way according to the geopolitical situation and the crucial role of Persian Gulf in the region, this golf is not safe against the effects of artificial islands construction and as a valuable ecosystem with high biodiversity has been threatened. Due to the growing trend of construction artificial islands in the Persian Gulf and importance of environmental risk assessment of these structures to analyze the relationships between the various stages of construction and environmental Persian Gulf, Fault Tree Analysis (FTA) was used in order to risk assessment of these structures. As a result it will follow path errors from an event or adverse condition (Top event) to achieving error or causal factors or initiator. The most important risks in Construction artificial island projects include: disorder in food chains, water pollution, hydrodynamic regime changing and damage to plant and animal species. Therefore for achieving sustainable development in the Persian Gulf, deciding about the construction of artificial islands must be more carefully and should be tried to reduce occurrence probability and severity of impacts.
\end{abstract}

Keywords: Artificial Islands, Marine Ecosystem, Persian Gulf, Fault Tree Analysis, Risk Assessment

\section{Introduction}

Growing Development of various sectors without adequate attention to environmental and social aspects makes some problems which it takes a lot of energy and money to remove them. While some of these developments impact may be Irrecoverable. An example of such development is the construction of an artificial island.

An artificial island is a man-made island which no natural processes is exist on it. This kind of island may be built on a rock in the sea or arise with spreading a small island [14]. Artificial islands in all over the world built alongside big and small cities in order to access a greater space for economic, social and political purposes. In many countries these constructions are considered as platforms for development of infrastructures such as airports, seaports, highways, etc. Also they have been used for reconstruction of indigenous areas and establishment of new tourist areas. Edge of the beach always is an interesting place for commercial, industrial and settlement activities. In addition water-related activities such as shipping, fishing, agriculture and coastal tourism has increased demand for expansion space in the cities and coastal countries. Population density in these areas is three times more than global average and migration from village to city makes it rise. This situation has created some challenges. In addition, geographical and political considerations increased the demand and make a lot of problems. That's why in some cases cities expand with building new territory within the sea [15]. Project of building artificial islands has been expanded along with tourism development in the countries of Singapore, Qatar, and the ${ }^{1} \mathrm{UAE}$ and especially in the Persian Gulf countries. It's a long time that these countries trying to dry up the sea in order to expand their lands. For this purpose there isn't any better way than building an artificial island. For drying the sea; soil, sand and

1- United Arab Emirates 
compressed clay poured in the shore and shallow water areas. To prevent degradation of soil particles by water we use a special texture that prevents water penetration to all particles. Persian Gulf countries can increase their lands kilometers with implementing this plan [4]. In general, building goals of artificial islands are vast and it's been developing in recent years with commercial, political and security purposes. In terms of morphology Goals, building artificial islands divided into five categories (fig.1) [22].

Most of new islands in Asia are artificial and are being used for purposes such as ports and airports construction. Also these islands are used to revive life-species and creating wildlife. Like spruce and Hart Miller Island. Islands such as Nakheel United Arabic Emirates in the Persian Gulf are built for tourism and commercial activities In addition to the aforementioned goals [20].

Building of artificial islands Began in the years of 1782 to 1983. On those years Salsa Island in Miami was composed from several small islands and to incorporate them a lot of hills became flat and the island Enlarged with filling shallow areas and linking islands to each other [14]. These islands constructions are increasing due to the tendency of rich countries to build them. It's an important matter to observe legal and international rules on these offshore structures. Under international sea laws size of the countries territorial sea is 12 nautical miles. After of this territory, there is

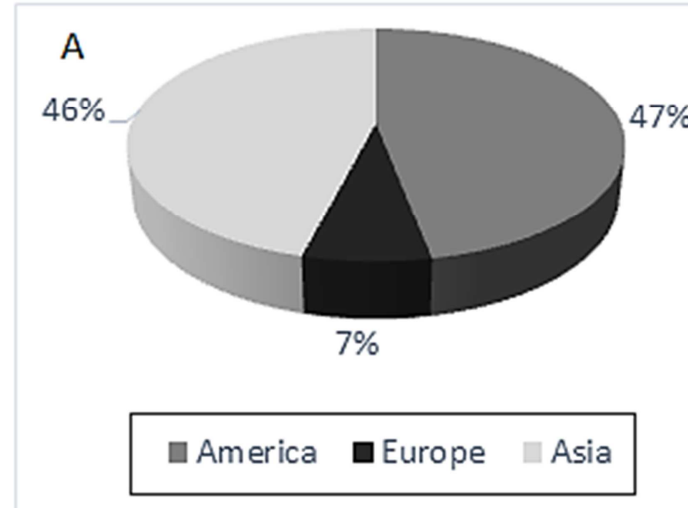

adjacent area which its surface area is 12 miles. After that exclusive economic zone begins. Exception of shipping on the exclusive economic zone and innocuous passage right through the territorial sea there isn't any right such as exploration, exploitation, cabling and etc. For other noncoastal countries in Persian Gulf and they should observe coastal State rules and regulations in accordance with Article 21 of the Convention relating to the navigation, protection of cables and pipes, fisheries, pollution, scientific research, brokerage, finance, immigration and health [16].To build artificial islands only coastal countries can proceed to build these structures in their own countries territorial sea.

Table 1. Categories of building artificial islands.

\begin{tabular}{|c|c|}
\hline First group & $\begin{array}{l}\text { Artificial islands and installations for the exploitation } \\
\text { and exploration of oil and gas resources, surfing and } \\
\text { fishing }\end{array}$ \\
\hline Second group & $\begin{array}{l}\text { Artificial islands for Economical activities such as } \\
\text { recreational-tourism harbour and human settlements }\end{array}$ \\
\hline Third group & $\begin{array}{l}\text { Artificial islands with military and government activities } \\
\text { goals such as the establishment of military installations, } \\
\text { establishing Prison and etc. }\end{array}$ \\
\hline Fourth group & $\begin{array}{l}\text { Artificial island for scientific usage such as installing } \\
\text { weather stations, biodiversity observation and etc. }\end{array}$ \\
\hline Fifth group & $\begin{array}{l}\text { Artificial islands as a base for industrial operations such } \\
\text { as steel plants, petroleum exploitation, coal mine } \\
\text { ventilation structures and etc. }\end{array}$ \\
\hline
\end{tabular}

B

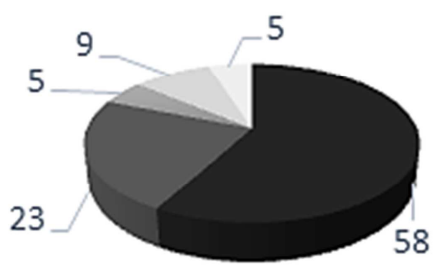

Environmental (2-8 km2)

- leisure- bussiness (1-10 km2)

- Port (1-2 km2)

Fig. 1. (A in left: Ratio constriction artificial islands in continents), (Bin right: Goals of building and exploitation of artificial islands).

As legally artificial island and its facilities is man-made and is surrounded by water from any direction at high tides and remains in a specific location for a specified time and acts as a station with its normal function. Artificial islands don't have an ability to obtain natural islands legal and ownership even during tides. This means that these islands don't have maritime zones belong to their ,such as territory sea (12 nautical miles), or in the public domain monitoring area (12 mile natural) and the exclusive economic zone (200 nautical miles of the coast or in the field).due to the authorities that the 1982 Convention has given to the coastal state in the exclusive economic zone including; the construction of artificial islands, They need safety belts which are as much as 50 meters [12].Generally based on the UN Convention on the sea Laws, the artificial islands are not considered as port installations(article 11)and they are under the jurisdiction of the nearest coastal countries conditioned that be located within the range of 200-mile natural(370 $\mathrm{km})$,(article 56).Artificial islands aren't like islands which have their own territorial sea or their own exclusive areas [1].

These islands building methods are also varied and different. So that the building methods are including; expansion of small islands, the integration of the natural islands and transforming into larger island and building on the seabed. These offshore structures are built of sand or gravel materials, conventional rock and concrete coastal engineering structures with the vision of design and construction and to choose an island form, Fields of cultural, social, symbols and innovative have a significant role. The size and location of coastal construction entails native, 
economic - social and political effects for adjacent areas [20]. Overall, in the design of artificial islands factors such as; water depth, wave height, ice conditions, tides range, earthquakes, resources and environmental conditions are affective. Consequently technical and environmental issues observation in the design and implementation of such structures are very important and comprehensive studies should be done about them [3].

Meanwhile, the buildings of artificial islands are as a serious threat for marine ecosystem such as Persian Gulf, and areas environment. in the step of construction and operation of these islands there are various economic, social and cultural effects such as increasing employment and living standards, creating residence, strategic facilities development, industrial and commercial development, secondary and not planning development in the area, acquisition of land use change and the positive and negative effects on the environment of area including air, water and noise pollution and destruction of vegetation and animal habitat and enhance the landscape. Marine pollution is one of the most significant environmental adverse effects in construction of artificial islands which causes destruction of biological resources in addition to temporary or permanent marine ecosystem damage. In this way, the artificial islands have a long-term effect such as; coastal streams changes, changing the type and severity of erosion and sedimentation, aggravate entry and it will have an accumulation of malicious pollutants in the environment during construction and after it. Therefore, considering devastating effects of the artificial islands on environmental, social and cultural factors are essential and important in order to manage, control and minimize them. In this regard, the identification, evaluation and risk assessment of environmental impacts of such projects is essential Due to their role in ensuring the sustainability of valuable ecosystems, such as the Persian Gulf.

Environmental risk assessment is the qualitative and quantitative analysis of the potential risk; determine the actual potential risk factors due to the implementation of the project and also the sensitivity and vulnerability of the environment [11]. Ecological risks can be studied in terms of probable risks on the environment, biological environment and vegetation. Today this process is becoming a management tool to solve environmental problems. Risk is defined as the adverse outcome of an activity or event along with its probability of occurrence. In environmental risk assessment in addition to analysis of various risk aspects, the sensitivity of the affected environment and the specific environmental values are also considered in analysis of the risk assessment with full knowledge of the affected environment [6].

Several studies which have been conducted about artificial islands, including; pishgahifar et al in 2011,they studied the effects and environmental and legal consequences of building artificial islands in Persian gulf and referred to some irreparable effects of such projects in Persian gulf [15]. Poorzaferani in 2012, studied methods of construction artificial islands and offered solution for reducing mental problems during construction of these project [18].

Also in recent years multiple studies on environmental risk assessment has been performed in different countries. Such as Hayes in a research with the topic of risk identifying in complex ecological systems which has evaluate the water balance with fault tree analysis method. It specified in an article that if fault tree analysis used for ecological systems it will have a significant potential exploration [5]. Also Mooret al in 1998 in a project titled Risk Assessment dredged and materials evaluate the environmental risks and dredging operations pollution due to dredging operations with using developed frank food network model. Aim of this study is to locating disposal of dredged material through tracing amounts of heavy metals in the food network. In their study the most important cause of pollution and toxicity is heavy metals within the sediments [3]. Christine et al (2009) in a study titled management dredging with environmental aspects, evaluates dredging risks and disposal materials and impact of these materials on the physical and chemical water quality, benthic aquatic and seabed habitats. The main risk in their study is destruction of seabed habitats and destructing benthic species Due to withdrawal and discharge of large sediment volumes [2]. Laribaghal et al (2011), in a study titled assessing environmental risk with FMEA; mining dredging jetties of Imam Khomeini port, environmental risks from dredging operations in jetties of this port with using analysis failure methods were evaluated. In the mentioned study we used Delphi questionnaires and in order to identify risk and to determine the probability of each risk occurrence, Analytical Hierarchy Process and Expert choice software was used. They specified available risks in physical and chemical, biological, economic and social environment during dredging operations in their results [10].

According to what was said, ecological risk assessment and understanding the effects of various activities in ecosystems especially sensitive ecosystems such as marine ecosystems is essential. This study has tried to express quantitative effects of total to component in the Chain of causation with fault tree analysis. In the following we will introduce them in detail. Risks identifying with this method can guide us in order to understand negative effects of activities and complication activities of Persian Gulf ecosystems protection and conservation.

\section{Materials and Methods}

Persian Gulf is a water zone with an area of 40 thousand square kilometers where almost all of it's around is surrounded by land and has just one way to the Indian Ocean from Hormoz strait. This Gulf is located in the dry tropics region and enjoys high temperature and evaporation. Its Species diversity is very high and has been considered as precious economic fisheries marine areas. It also has a variety of ecosystems such as coral reefs, Alga plants, mangroves and mangrove and etc. which has created unique natural attractions [16]. In addition to the geopolitical and 
strategic importance of Persian Gulf it's important as a highly valuable ecosystem. For example, there are more than 450 species of fish, variety of delicious shrimp, precious and rare species of the world and also a Nurturing environment for the best natural pearls in the world, the best lobster and other valuable aquatic organisms which are special of this water ecosystem [9].

Due to natural attractions and geopolitical conditions governing this zone it becomes more considerable in recent years that's in the past years, some countries such as UAE is building three large artificial island in the Persian Gulf with economic investment. These actions encourage other countries to build an artificial island [16].Due to the growing trend of building artificial islands in the Persian Gulf and the importance of environmental risk assessment Mentioned, in this regard in this study environmental risk assessment of these structures in Persian Gulf are discussed. To achieve this goal to get basic information, we use library studies and to assessment of structure environmental risk and analysis of relations, fault tree analysis $\left({ }^{2}\right.$ FTA $)$ has been used.

Table 2. Concepts used in this research are.

\begin{tabular}{ll}
\hline Top Event & $\begin{array}{l}\text { Event that is placed at the highest point } \\
\text { of the fault tree and its causes are } \\
\text { identified and analysed } \\
\text { An event that happens between two other } \\
\text { events. a fault event that occurs as a } \\
\text { result of the logical combination of other } \\
\text { events } \\
\text { an event which is normally expected to } \\
\text { occur (not a fault event) }\end{array}$ \\
$\begin{array}{ll}\text { Entermediate } \\
\text { External event }\end{array}$ \\
Basic Event & $\begin{array}{l}\text { Each basic-level events that cannot be } \\
\text { explained more }\end{array}$ \\
Undeveloped & $\begin{array}{l}\text { Each basic-level events that Not be } \\
\text { analysed more because of various } \\
\text { reasons } \\
\text { the output occurs only if all inputs occur } \\
\text { (inputs are independent) }\end{array}$ \\
(And gate) & $\begin{array}{l}\text { Transfer symbols are used to connect the } \\
\text { inputs and outputs of related fault trees, } \\
\text { such as the fault tree of a subsystem to its } \\
\text { system. }\end{array}$ \\
(Or gate) &
\end{tabular}

Fault tree analysis was fully identified in the mid-1960 and was originally developed in 1961 Bell Laboratories by H.A. Watson, in 1962 under a U.S. Air ForceBallistics Systems Division contract to evaluate the Minuteman IIntercontinental Ballistic Missile (ICBM) Launch Control System. After the Challenger incident in 1986 Stamatelatos $\&$ et al realized the importance of probabilistic risk assessment and fault tree analysis and used them. After Three Mile Island incident in 1979,nuclear industries started using probabilistic risk assessment techniques such as FTA [21].In this method top-down evaluation is used and it's assumed

2- Fault TreeAnalysis that error occurred in the system and trying to find the affecting factors in these errors. As a result, it will follow the error routes from undesirable and predetermined event named top event until reach the errors which named initiator factors. When this method is applied on the system it could be used to identify the best ways to reduce risk or to determine (or get a feeling for) event rates of a safety accident or a particular system level (functional) failure. Fault tree analysis method using causal relationship and with using of symbols various activities impacts are identified. (Figure 2 and Table 2)

\section{Results}

Constructions of artificial islands have several steps which briefly comprises the following steps. Dredging: transport marine materials from one part of sea to the desired location by special vessels are said dredge. There are three common methods for dredging including: suction dredging, shear and suction-shear. Which choosing any of the methods is vary depending on the project [18].

Putting filler materials in the sea floor: after dredging the material and transfer it to the site, filler materials putting on the sea floor with different methods according to geographical location and type of existing materials. Including activities performed in this section can be regarded as; discharged materials by ship with lower grille, side discharge, spray material pump, underwater pipes, cone valves, tube surface, Hydraulic Excavator. After discharging filler material in place and achieve the desired balance of the island, its surface becomes dense and soil characteristics will improve with using modification methods [3-7].

Erosion and scour protection: to eliminate power waves and prevent erosion and scouring materials breakwater or sea wall should be used. Using either types can immune the island from winds and powerful marine streams. Breakwater and sea walls consist of several layers of sand, rock fragments, layers of reinforced stone and concrete blocks. These structures can be used before or after putting the filler materials of the island. But in general the sea walls are constructed before construction of the main body of the island and determined the boundary of island. But breakwaters mounted during or after completion of body construction and the formation of island's coastline [8-19].

Liquefaction: soil Liquefaction is a phenomenon in which saturated soil lost its resistance suddenly due to the seismic loading and shows a Liquefaction manner. This phenomenon often occurs in non-cohesive soils with the dynamic loadings. However, in most soils we can see this phenomenon with static and dynamic loadings [17].

Subside: in general subside have three steps of; immediately, primary strengthen and secondary strengthen. In construction of artificial islands estimates and controls of strengthen subsides are so important. Subside amount is depends on the soil amendment and whatever the amendment done wider subside will be reduced [23].

Each of mentioned steps has a complex and specialized 
process. Meanwhile according to the Persian Gulf which is an alive and dynamic ecosystem, expected that these changes effect on organisms, ecosystems and some physical processes. Construction of artificial islands can effect on the physical, chemical and biological factors. These factors changes may lead to turbulence in the food chain, impaired in reproduction and migration and etc.

The most important environmental and ecological impacts of construction and operation of artificial islands are noted as follows:

1. Threat of migratory of bird's sanctuary and uninhabited islands by disrupting their balance and habitat destruction.

2. destroying coral ecosystems as one of the vital Persian Gulf's ecosystem ,destroying habitat of other animals such as fish, crabs and ...
3. Changing in seabed

4. Enter the variety of anthropogenic pollutions in to the Persian Gulf's marine waters.

5. Changing marine streams due to sediment disturbance and physical barriers

6. Increasing sediment loads in some marine areas due to the disruption of normal flow

7. Increasing exposure of natural disasters like marine hurricanes and tsunamis and....

8. Erosion of coastlines

In addition to mentioned cases, project of the construction of artificial islands can have a legal and political effect and Consequences which they are ignored in this study. Habitat degradation is the most important effect of this project. That according to chain of causation its risk trees in various stages will look like this: (Fig 3.1- 3.4)

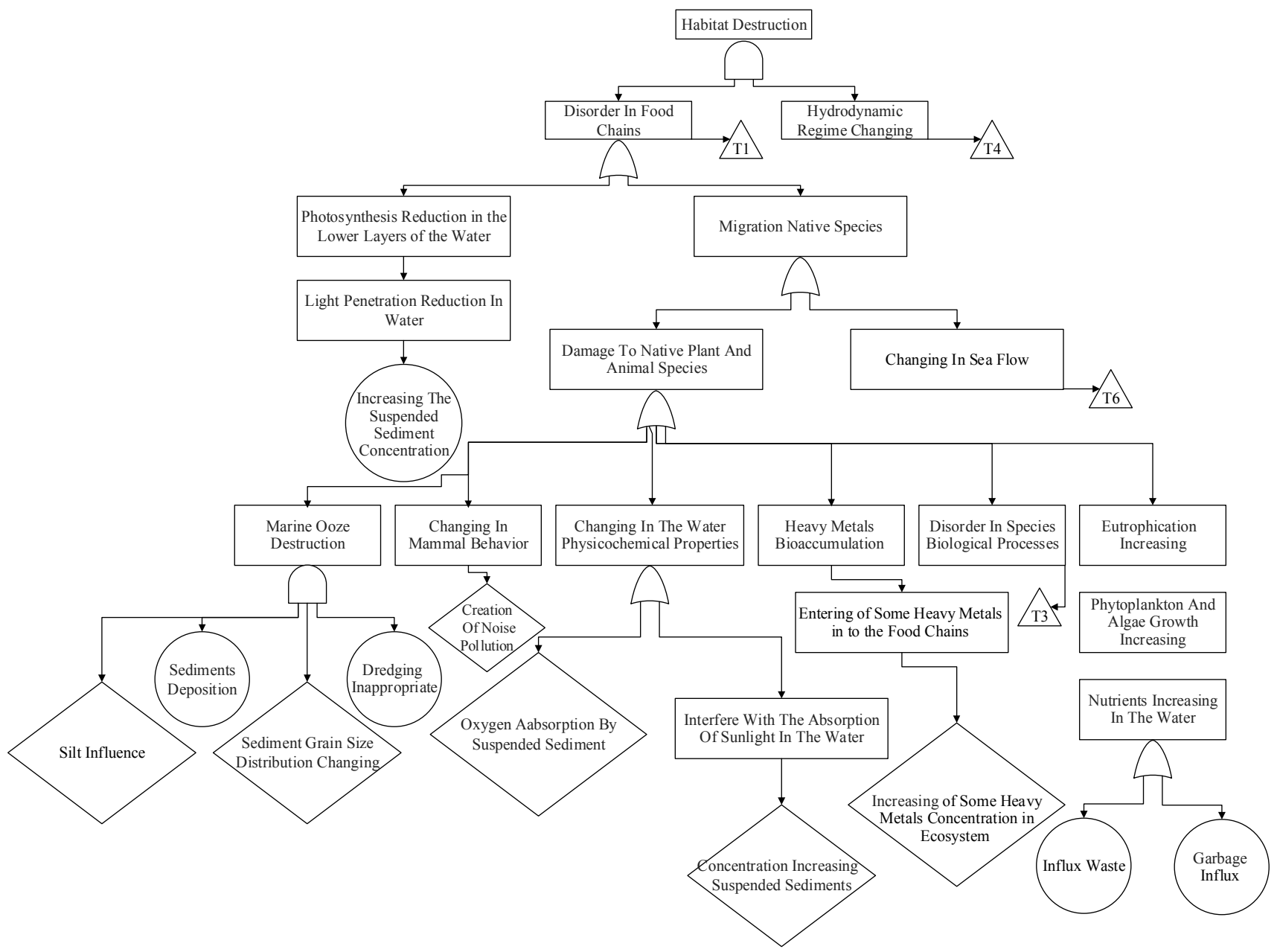

Fig. 3.1. Fault tree analysis diagrams. 


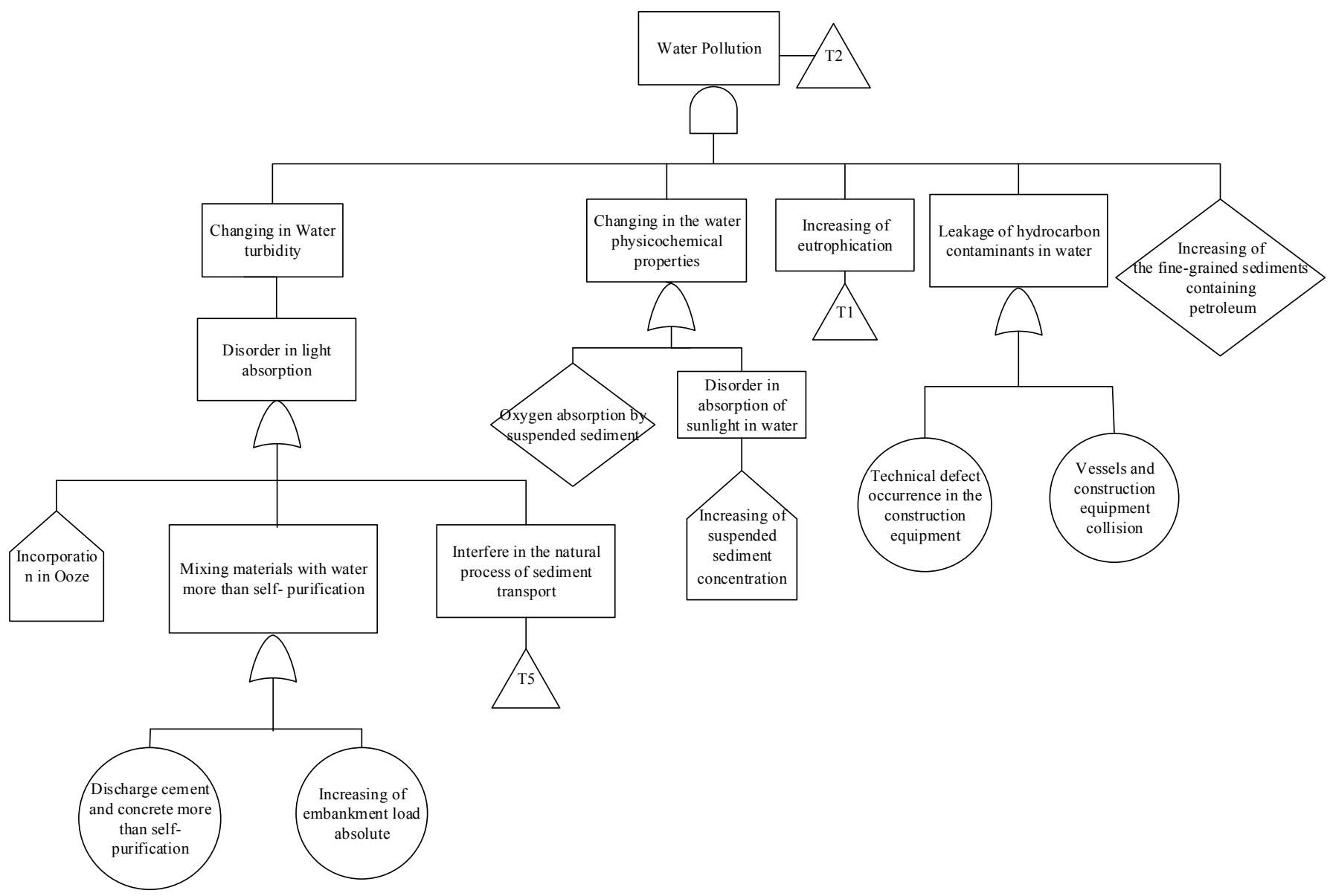

Fig. 3.2. Fault tree analysis diagrams.

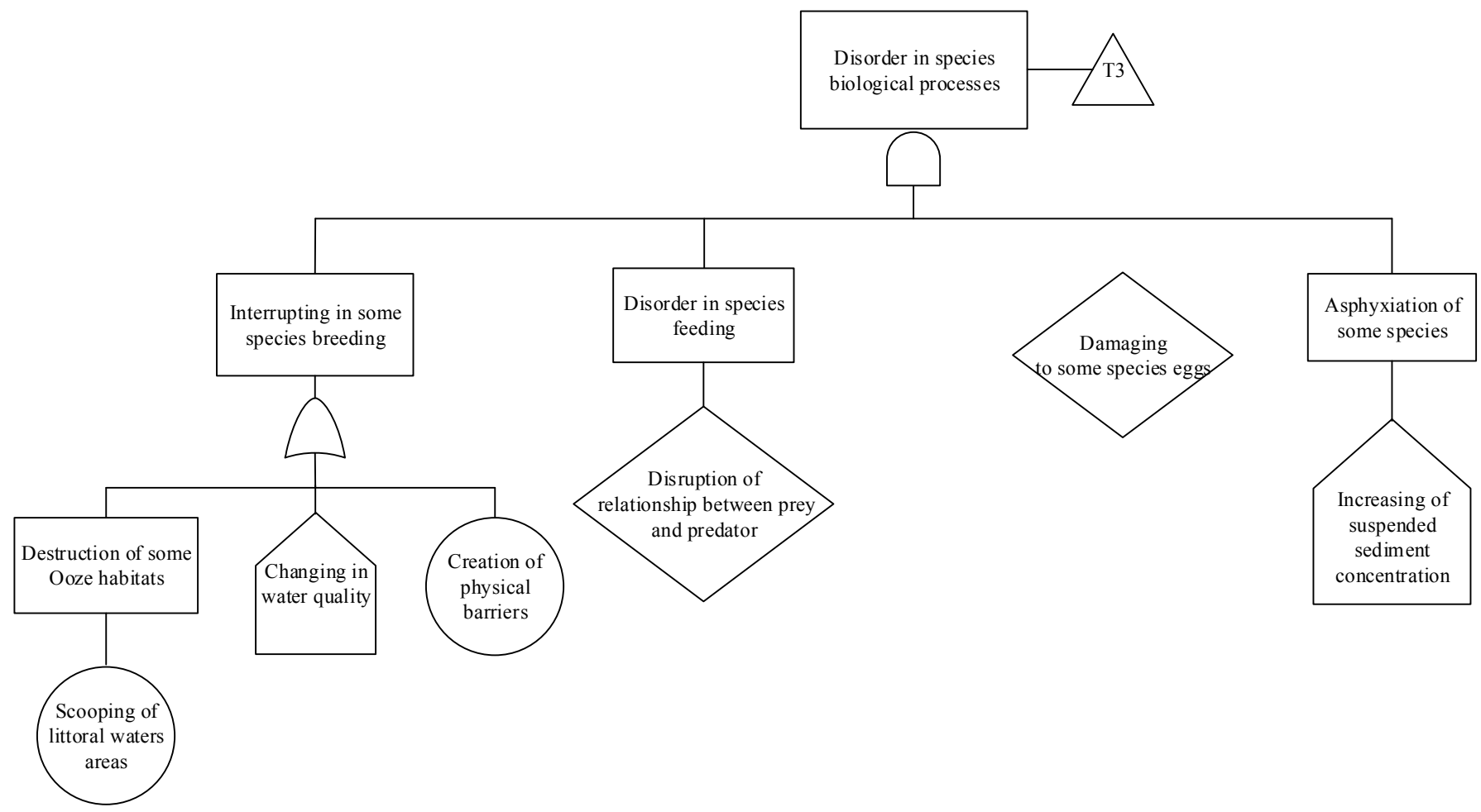

Fig. 3.3. Fault tree analysis diagrams. 


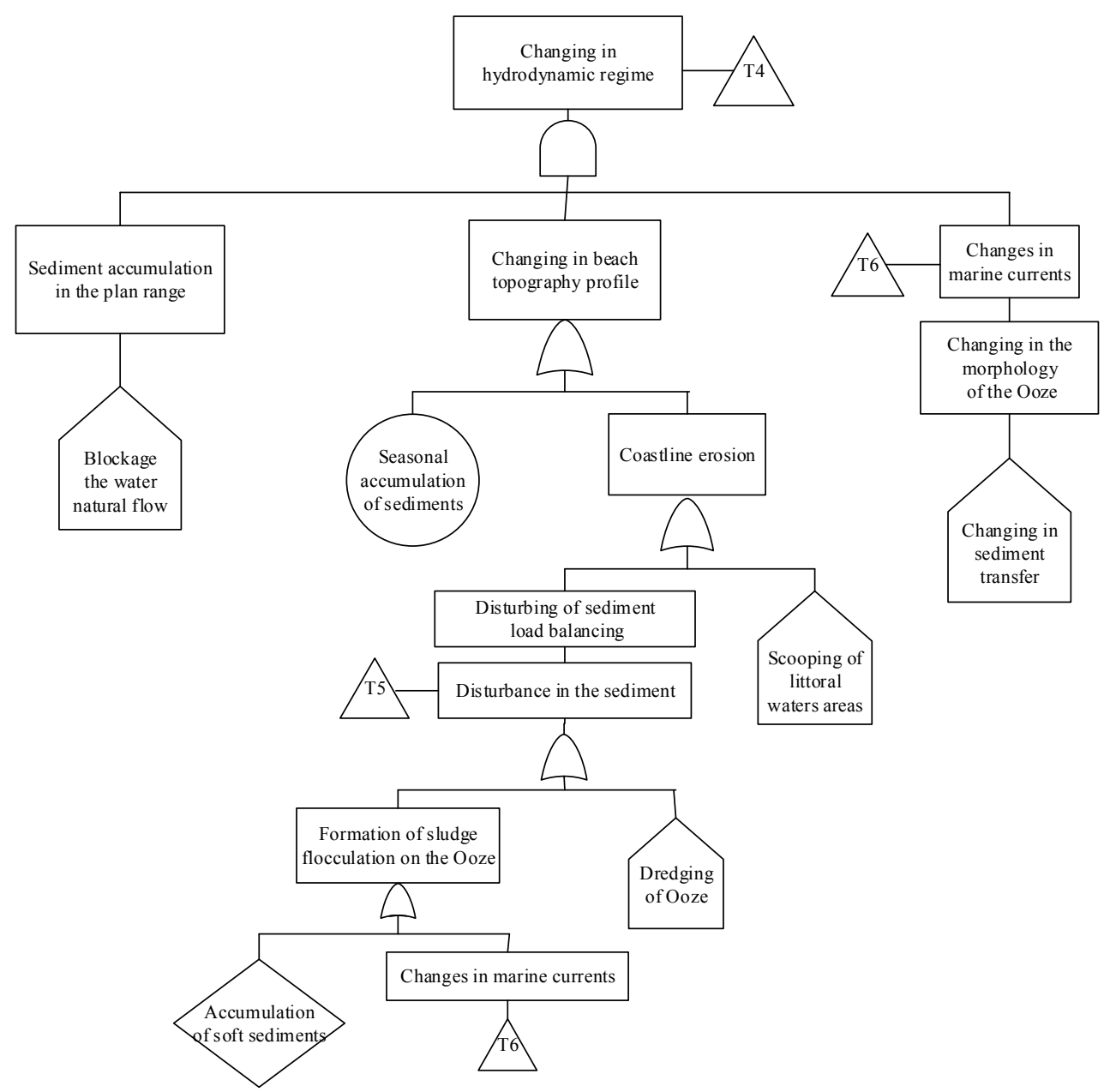

Fig. 3.4. Fault tree analysis diagrams.

\section{Discussion}

Overall, results of fault tree analysis specified effects of construction of artificial islands and associated risks as a topdown. Also high level risks of a tree are much more destructive in Persian Gulf's ecosystem. Destruction of habitats and Persian Gulf's ecosystem are the main event of this project which this event is a function of low level risks. Low level risks can cause a greater risk at higher levels with their impacts with each other. According to the fault tree depicted for the construction of an artificial island project in Persian Gulf, the important effects and the main risks arising from this project can include; disruption of food chains, water pollution, hydrodynamic regime change and damaging marine organisms. Mentioned risks are the factors which will affect the Persian Gulf region with the construction of an artificial island. These materials in low level of tree as the cause and effect relationship includes Cases such as; migration, marine streams change, sediment transport disturbance, turbidity and disturbance of animals replication cycle. According to prioritize greatest risks of construction of artificial islands in the Persian Gulf are; disturbances in the food chain, beach topography's change, choking fishes and absorption disturbances.

\section{Conclusion}

Thus providing control solutions for the proper management of mentioned risks is important and can help to preserve Persian Gulf's natural conditions. Considering the importance of Persian Gulf ecosystem, it's maintaining provides food security and employment for Indigenous. Also it's important in maintaining species diversity as a unique habitat and genetic reserve in the international level. Reducing mentioned risks can be associated with the application of new technologies which have less damaging results. Also we should have a systematically locating for construction of island to be far from the sensitive ecosystems migration and replication locations. Also the structures should be selected so that creates least disruption in marine streams. In General, with respect to certain environmental criteria we can reduce Damaging effects of construction of an artificial island. But preventing some of these types of projects effects and risks in marine ecosystems especially in Persian Gulf is inevitable. And we should decide carefully on an artificial island projects in order to achieve sustainable development in Persian Gulf marine ecosystem. 


\section{Acknowledgment}

We are grateful to the Dr. Niksokhan and Dr. Yavari for their constructive suggestions on the early draft for preparation of manuscripts.

\section{References}

[1] Aghai. B, Artificial Islands in the Persian Gulf and the International Law of the Sea, Persian Journal, 1, 2006, 2-5.

[2] Christine. A, Axel. N, Dredging management practices for the environment: A structured selection approach, Terra ET Aqua, $114,2009,3-8$.

[3] Gerwick. C, Ben Construction of Offshore Structures, John Wiley and sons, USA, 1987.

[4] Hashemi. H, Construction ofartificial islands, trade with environment, www.aftab.ir, Revised December 2009, Accessed October 18, 2014.

[5] Hayes. K.R, Identifying hazards in complex ecological systems. Part 1 fault-tree analysis for biological invasions, Biological Invasions, 4, 3, (2002), 235-249.

[6] Heller. S, Managing industrial Risk-having a Tasted and Proven system to prevent and assess Risk, Journal of Hazardous Materail, 130, (2006), 58-103.

[7] Horii. R, Historical background and recent trends in dredging and reclamation technologies in Japan, Marine Georesources\&Geotechnology, 14, (1996), 19-36.

[8] KALD,Kansai Airport Land Development Company,www.kald.co.jp, Revised December 2009, Accessed December 18, 2013.

[9] Kardovani.P,2009, StrategicDevelopments inplacein the Persian Gulfregion, Proceedings of the conference onstrategicdevelopments inthePersian GulfPlace, Tehran, Geographic and Cartographic Institute Publications Gitashenasi, special Issue1 (2009)

[10] Laribaghal. M, Jafarzadehaghighifard. N, RafieUsing. M, FMEAinenvironmentalrisk assessment: the case ofmining,dredgingsome docksBandar imam Khomeini, WetlandResearch, 9, (2011), 14-3. (In Persion)

[11] Muhlbauer. W, Pipeline Risk Management Manual. Gulf Professional Publishing, 3, (1999), 65 - 75.
[12] Mirheydar. D, the Foundations of Political Geography, Tehran, Iran, 2011.

[13] Moor. D.W, Bridge T.S, Wes. C.R \& et al, Environmental Risk Assessment and Dredged Material Management: Issues and Application, Dredging Operations and Environmental Research Program, http://el.erdc.usace.army.mail/elpus/pdf/trdoer2.pdf, 1998.

[14] Omidi. A, International Law and the Construction of Artificial Islands, Information of Political -economic, 237-238, (2007), P. 73-77. (In Persian)

[15] Pishgahifard. Z, Kamran. H, Afzali. R, Hoseiniaminy. H, Eltiyamniya. R, Legal andenvironmental consequences ofthe construction ofartificial islandsin thePersian Gulf, Institute ofHuman Geography, 79, (2011), 140-117. (In Persian)

[16] Pishgahifard. Z, An introduction to political geography of seas with emphasis on Iran's seas, University of Tehran Press, 2005. (In Persian)

[17] Polito. C.P, The effects of non-plastic and plastic fines on the liquefaction of sandy soils, PHD Dissertation, Faculty of the Virginia Polytechnic Institute, (1999).

[18] Poorzaferani. M, An overview of methods for the design and construction of artificial islands, and measures to reduce liquefaction potential and meeting, $10^{\text {th }}$ International Conference on Coasts Ports and Marine Structures,October, in Tehran, Iran, 2013. (In Persian)

[19] Puzrin. A. M, Alonso. E. E., Pinyol. N. M, Unexpected Excessive Settlements: Kansai International Airport, Geomechanics of Failures, Springer, Germany, 2010, 23-43.

[20] Rabionet. I, Indicators for Evaluating the Impact of Artificial Islands on the Barcelona Coast, Coastal Management, 36(3), (2008), 254-273.

[21] Stamatelatos. M, Caraballo. J, Probabilitic risk assessment procedures guide for NASA managers and practitioners,office of safety and mission assurance NASA headquarters, www.hq.nasa.gov/office/codeq/doctree/praguide.pdf, Revised Augest 2002, Accessed June 3, 2012.

[22] Tsaltas. G, Bourtzis. T, Rodotheatos. G, Artificial Island and Structure as a Means of Safeguarding State Sovereignty Against Sea Level Rise, A law of Sea Perspective, , document in preparation of the 6th ABLOS Conference,(2010), Monaco.

[23] Yasuda. S, Ishihara. K, Harada. K, Shinkawa. N, Effect of soil improvement on ground subsidence Due to liquefaction, Soils and Foundations, special Issue1, (1995), 99-107. 